\title{
Revisiting the distinction between accomplishments and achievements
}

\author{
Fabienne MARTIN
}

Universität Stuttgart ${ }^{1}$

\section{Introduction}

As is well known, Vendler (1957) proposed to distinguish between two classes of telic predicates, namely, accomplishments (eat an apple, draw a circle), denoting durative events, and achievements (reach the summit, win the race), denoting punctual ones. As Kearns (2003) has recently emphasized, Vendler adopted this distinction from Ryle (1949), who already distinguished " task verbs" like search or participate, which denote an action, and « achievement verbs » or « failure verbs » like find or lose, which denote a possible achievement (or failure) obtained through this action. The term achievement suggests by itself that Ryle's distinction is not merely a temporal one, as Vendler's one is.

As is well known too, the distinction between accomplishments and achievements has been criticized for several reasons. A first counterargument is proposed by Verkuyl (1972), and developed further by Egg (1995). According to them, punctuality is an extra-linguistic property of situations, not a linguistic feature. To repeat one of Verkuyl's example, draw a circle denotes a durative event if the circle is drawn with a pencil, but can arguably denote a punctual one if it is drawn with a computer. Hence, this predicate cannot be assigned a value for the punctuality feature in its semantics.

Several authors have provided strong arguments in defense of the original Vendlerian distinction, and, in particular, against this first counterargument. Pursuing an intuition of Freed (1979) and Mittwoch (1990), Piñón (1997) rejects the definition of punctual events denoted by achievements as "very short» events, and take them literally as events without any duration. Under this second definition, events denoted by achievements are not « instantaneous » in the same sense than flashings or

\footnotetext{
This work has been carried out as part of the project B5 (SFB 732) supported by the German Science Foundation. I am grateful to Christopher Pinón for several discussions on almost every topic addressed here and for his proofreading work. I also thank Stefan Engelberg, Tolgrim Solstad and the reviewers for their valuable comments. All shortcomings are mine.
} 


\section{Fabienne Martin}

blinkings are: in the latter case, this adjective means " extremely short», while in the former, it means literally « durationless ». On this perspective, flash or draw a circle are not achievements in any context, since they denote at best extremely short events, but never (literally) durationless events ${ }^{2}$.

In rejecting the idea that punctual events denoted by achievements are very short events, Piñón can be seen to follow Ryle, as illustrated by the following lines (the italics are mine) :

" "I began to [reach the conclusion], but had not time to finish" is not the sort of thing that can significantly be said. In recognition of this kind of incongruity, some theorists like to describe [reaching a conclusion] as an instantaneous operation, one which, like a glimpse of a flash, is completed as soon as it is begun. But this is the wrong sort of story. The reason why we cannot describe [reaching] a conclusion as a slowish or quickish passage is not that it is a "Hey, Presto" passage, but that it is not a passage at all. [...] reaching a conclusion, like arriving in London, solving an anagram, and checkmating the king, is not the sort of thing that can be described as gradual, quick, or instantaneous. We can ask how long it took to run a race, but not how long it took to win it. Up to a certain moment the race was still in progress ; from that moment the race was over and someone was the victor. But it was not a long or short moment. » (Ryle 1949 : 284, italics are mine)

Clearly, Ryle wanted to avoid the (already classical) confusion of events denoted by achievements with very short events and emphasized their « zero duration » property.

Piñón proposes to add boundaries in the realm of events, and defines durationless events denoted by achievements as the boundaries of «thick » events in their vicinity. Some predicates denote the right boundary (or end) of a thick event, like win the race which denotes the right boundary of the race itself. Others denote the left boundary (or beginning) of a thick event, like begin to read the book which denotes the left boundary (or beginning) of the reading. Following Zybatow (2004), I propose to call predicates of the first kind right achievements and the others, left achievements.

Defining achievements as durationless events allows Piñón to explain some specific properties of the corresponding predicates. Firstly, it is predicted that they are incompatible with adverbs of completion like partially/partly, at least when these adverbs have scope over the event, since a durationless event cannot have parts $(c f .(1)-(2))$. With these predicates,

2 Note that flash or explode are classified as achievements for those authors like Tenny (1987) or Egg (1995) for whom achievements and accomplishments only differ by the length of the process. These predicates are not achievements in Piñón's typology. Vendler also excluded predicates like flash or explode in his examples of achievements, which suggests that he did not conceive them as parts of this class either. 
adverbs of completion have no other choice than having scope over the object, which is possible in (2), but not in (1), since it's implausible to reach parts of a summit.

(1) \# He partially/partly reached the summit.

(2) He partially/partly reached the same conclusions as me.

Secondly, one explains why achievement predicates are incompatible with agentive adverbs like carefully, once we admit, which seems reasonable, that any action takes at least some time to be performed (cf. (3)) :

(3) $*$ He carefully won the race.

Thirdly, it is predicted that the same predicates cannot be embedded under aspectual verbs like stop or finish, because one cannot stop or finish a process which has no duration at all :

(4) * He stopped reaching the summit.

(5) * He finished winning the race.

However, there is at least one important fact that the aforementioned analysis does not account for so easily, and this leads us to the second counterargument often raised against Vendler's distinction, namely, that contrary to what Vendler suggested, achievement predicates are perfectly compatible with the progressive :

(6) He's finding his key.

As events with no duration are never in progress, the argument goes, achievements cannot denote durationless events, since they are compatible with the progressive. It is on this basis that authors like Parsons (1985) give up the idea that achievements and accomplishments form two different semantical classes.

Piñon tries to turn the table around and suggests that the compatibility with the progressive can, on the contrary, support the idea that achievements form an aspectual category on their own. His idea is that progressive confirms that achievements differ from other telic predicates because there is always an unpredictable meaning change once they are progressivized. For instance, Piñón suggests that Peter was winning the race does not mean that the winning is in progress, but is better paraphrased as Peter is leading the race.

Indeed, it seems clear that achievement predicates differ from other predicates in progressive sentences. However, this intuition would be grounded on a firmer basis if one could state more explicitly in which sense 


\section{Fabienne Martin}

achievement progressive sentences « do not imply a progress » as standard progressive ones (why the winning is in progress is not an accurate paraphrase of Peter was winning the race) ${ }^{3}$. The idea of a meaning shift raises a more serious problem. If, in reality, a predicate like reach the top means something like approach the top in progressive sentences, one predicts that in principle, the former should have the same distribution as the latter in these contexts. However, this is not the case, as suggested by the following contrast :

(7) * He stopped reaching the top.

(8) He stopped approaching the top.

In the following section, I propose to account for the compatibility of achievements with the progressive in a different way. Basically, the strategy is to admit that any (punctual) achievement can be coerced into a durative achievement by the progressive or other constructions demanding a nonpunctual predicate, and to explain why the result of this coercion is sometimes not acceptable for independent reasons (e.g., with stop or partially/partly). On this view, achievements are different from accomplishments even when they are durative; the compatibility with «durative-only» constructions is not an argument against the class of achievements anymore. In section 3, I show that two sub-classes of accomplishments share some features of durative achievements (although different ones for each subclass). Briefly, what I propose to call « resultative accomplishments » like kill the cat are not acceptable either with partially or stop (cf. (9)-(10)), whereas « strictly strong accomplishments » like cure or convince are not compatible with agent oriented adverbs and presuppose $\left(\rightarrow_{P}\right)$ an event (cf. (11)-(12)). It will be shown that the last feature is also one of the benchmarks of (punctual or durative) achievements. The data used will be mostly borrowed from French.

(9) * Peter partially killed her cat.

(10) ?* Peter stopped killing her cat.

(11) ?? The doctor cured/convinced me carefully.

(12) The doctor didn't cure/convince me.

$\rightarrow_{P}$ The doctor did something (i.e., he treated me/tried to convince me)

3 Kearns (2003) also states that the progressive with achievement predicates is not the standard progressive. But her inventory of achievements is quite different from the one of Piñón, because she includes in this class every Rylean achievement (and some of them like prove are analysed as accomplishments by Piñón 1997). 
Revisiting the distinction between accomplishments and achievements

\section{Durative achievements}

\subsection{Introduction}

The idea that the aspectual classification should be enriched with a class of durative achievements has already been proposed by Caudal (1999) and Kearns (2003). However, while these authors suggest that some achievements are lexically marked as punctual and others as durative, I suggest that any punctual achievement has a coerced durative correspondent. I will restrict my attention to right achievements, because they are the easiest to confuse with accomplishments ${ }^{4}$.

Another reason to admit that achievements can be coerced in durative predicates apart from their compatibility with the progressive is that contrary to what is often stated, they are acceptable with some aspectual verbs like commencer (begin) or achever/finir (finish). See, for instance, the following examples (all taken from the literary corpus Frantext or Internet) :

(13) Il avait déjà commencé à trouver en chemin la paix et la charité. (L. Bloy)

He already begun to find peace and charity on his way.

(14) Le rat blanc avait commencé à perdre la vie. (J.-M. Le Clézio)

The white rat had begun to lose life.

(15) Voulez-vous achever de perdre Léonore ? (P.C. de la Chaussée)

Do you want to finish losing Leonore?

(16) J'ai une carte Wifi qui marche une fois sur deux, enfin quand elle a fini de trouver la source après une heure de scan. (Internet)

I have a Wifi card which works one time out of two, well, when it has finished finding the signal after one hour of scanning.

(17) Mais j'étais aussi trop heureux dans ma solitude pour y achever de mourir en paix. (G. Bernanos)

But I was also too happy in my solitude to finish dying there in peace.

(18) Je garde la nostalgie des longues chevauchées en compagnie de mon grand copain Dédé, des pannes dans la campagne obscure, lorsqu'il fallait remettre la chaîne en place pour achever d'arriver au bal. (Internet)

$4 \quad$ As observed by Zybatow (2004), only right achievements are compatible with the standard reading of in-phrases ( $c f$. He arrived in Belgium in three days). Left achievements are either unacceptable with these adverbs, or select their « ingressive » reading (in this case, the in-phrase does not measure the length of the process anymore, but the time needed to begin it (cf. He left Brussels in three days). 


\section{Fabienne Martin}

I keep the nostalgy of long rides with my tall friend Dédé, of breakdowns in the dark countryside, when one had to put the chain in the right place in order to finish arriving at the ball.

As already mentioned earlier, one cannot begin or finish a durationless process. Thus, if achievements are acceptable with these verbs, it is because they can get coerced by them into durative predicates.

Admitting that achievements can be coerced has a big price though. Firstly, one cannot explain their remarkable distribution (no compatibility with adverbs of completion, agentive adverbs, aspectual verbs, etc.) anymore by their durationless property only. Piñón's analysis accounts for the incompatibility of these contructions with punctual achievements, not with durative ones. Secondly, one jeopardizes once again the distinction between accomplishments and achievements, since punctuality cannot make the difference anymore. In the next section, I show that coerced achievements still differ semantically from accomplishments and explain why coercion does not give systematically acceptable results by identifying independent parameters at play.

\subsection{Durative achievements versus accomplishments}

\section{Presupposition}

A first feature that differentiates right achievements from accomplishments is that they presuppose $\left(\rightarrow_{P}\right)$ the occurrence of an event. This has already been observed independently several times for punctual right achievements ( $c f$. Engelberg 1999, 2000, Caudal 2002, Zybatow 2004, Kearns 2003, Malink 2007, Piñón 2007a). Negative sentences and other classical presuppositional tests support this claim :

\section{Pierre ne m'a pas persuadé.}

Pierre didn't persuade me.

$\rightarrow_{P}$ Pierre did something that could have persuaded me.

Il est possible que Pierre ait gagné la partie.

It is possible that Pierre won the game.

$\rightarrow_{P}$ Pierre did something (e.g., he participated in the game).

The event presupposed is generally an action of the subject that has or could have had (in positive and negative sentences, respectively) the boundary of type $P$ denoted by the predicate. Note that accomplishments or activities generally do not trigger a presupposition $\left(/ \rightarrow_{P}\right)$ of this kind :

$$
\text { Il est possible que Pierre lui ait parlé/ait participé au jeu. }
$$


It is possible that Pierre talked to him/played the game.

$/ \rightarrow_{P}$ Pierre did something.

If sentences (19)-(20) are put in the progressive, they still presuppose the occurrence of an event (which is in progress), which is not true of (21). For instance, Peter is not winning the game presupposes Peter is participating in the game. This suggests that durative achievements presuppose an event too, contrary to accomplishments.

\section{Non-implicative progressive}

As is well known, progressive accomplishment sentences do not imply the truth of the corresponding perfect sentences; for instance, there is no entailment from (22) to (23). This is what is behind the so-called the imperfective paradox.

(22) Peter is eating a sandwich [in $t]$

(23) Peter ate a sandwich.

(24) Peter partially ate a sandwich [in $t]$

However, this does not prevent progressive accomplishment sentences from entailing the occurrence of an incomplete event. For instance, (22) entails (24). Let's call the implicative progressive the progressive implying the occurrence of an incomplete event. Now, we can observe that applied to (right) achievements, the progressive is never implicative. For instance, (25) does not entail (26). Arguably, it is the absence of this entailment which underlines the intuition that the progressive of achievements « does not imply a progression $\gg$ :

\section{Peter is finding the key [in $t]$}

(26) The finding of the key by Peter is partially completed [in $t]^{5}$

Note that if (25) does not denote a part of an event that would possibly satisfy the predicate find, it still presupposes the occurrence of an event (e.g., a search), as just mentioned above. This is why we can still doubt that progressive achievement sentences «are not progressive» at all. They do suggest that an event is in progress (like a search in (25)), but do not entail a part of a possible event satisfying the predicate, contrary to what happens with accomplishments.

A legitimate question is the following : why do progressive achievement sentences block the entailment? What is proposed here is that the feature of

5 Of course, I avoid the partially-contruction used in (24) to test the entailment, since adverbs of incompletion are unacceptable with achievement verbs. 


\section{Fabienne Martin}

achievements responsible for it is of an epistemic nature. In two words, durative achievements denote « epistemically uncontrollable events ", that is, events such that one cannot know that they are partly realised at a point $t$ before they are completed (at a point $t^{\prime}$ posterior to $t$ ). For instance, it is generally not possible for a normal non-omniscient epistemic agent to know that Peter has partly performed the finding of the key before Peter has actually found it (has performed the complete finding). One has to wait for the end of the finding in $t^{\prime}$ in order to know that what was already done in $t$ was a part of a finding. Before $t^{\prime}$, we can at most guess or bet it will be the case, but not know it the way we know that Peter partially ate a sandwich once we know he is eating it.

It should be noted that there is a difference between this and the imperfective paradox found in accomplishment sentences like Peter is crossing the street. To be sure, if this sentence is true, one cannot be certain that Peter will reach the other end of the street, but what is known, however, is that Peter partly crossed the street. In two words, progressive accomplishments are «epistemically controllable to the left» and « epistemically uncontrollable to the right», while progressive achievements are « epistemically uncontrollable » on both sides.

As an a contrario evidence of the fact that it is the lack of epistemic control to the left which blocks the entailment above, let us imagine that (25) is asserted in a community of omniscient gods, knowing everything about the mereological relations linking past, present, and future events. In such an exceptional epistemic context, it seems that (25) entails knowing (26).

\section{No adverbs of attention}

Coerced achievements are not acceptable with at least some agentive adverbs like attentivement (carefully), as illustrated in (27). This is another feature distinguishing them from accomplishments.

$$
\begin{aligned}
& \text { * Il est en train de gagner attentivement la partie. } \\
& \text { * He's winning the game carefully. }
\end{aligned}
$$

In my view, the problem of (27) does not come from the fact that durative achievements never denote actions. In fact, they do : why would a (durative) winning be banned from the realm of actions? If they were, why can we say something like What I did was to find the solution? And why are they compatible with some agent-oriented adverbs like intelligemment (cleverly), as observed already by Jayez (1996) ${ }^{6}$

As is well known, adverbs like cleverly have a manner reading (paraphrasable by in a clever way) and what Geuder (2000) calls the agentive reading (paraphrasable by it was clever of him that...). In what follows, I exclude the 
Revisiting the distinction between accomplishments and achievements

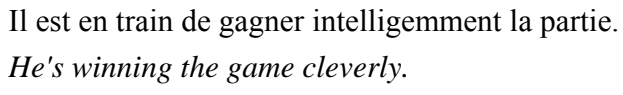

To be sure, the actions denoted by achievements are special though, in the sense that, as already suggested above, they cannot be «epistemically controlled » by their agent : generally, we cannot know we are performing a winning while performing it. In that sense, durative achievements denote less prototypical actions. What is proposed here is that contrary to other agent oriented adverbs like intelligemment (cleverly), adverbs of attention like attentivement (carefully) are unacceptable with durative right achievements because they are precisely associated with the inverse epistemic value. More particularly, they suggest that the entity denoted by the subject « knows what he is doing while doing it ». In favour of this hypothesis, it can be observed that when the context makes clear that the performer does not know that he is performing an action of the relevant type $P$ while doing it (because it is not a cognitive entity for instance), then this performer cannot be said to act carefully. For instance, (29) is acceptable only in a context where the computer is personalised (note that the activity predicate traiter "process » is chosen to illustrate that carefully-adverbs do not display this epistemic value only with achievement predicates)

$$
\begin{aligned}
& \text { \# L'ordinateur a traité le problème attentivement. } \\
& \text { \# The computer processed the problem carefully. }
\end{aligned}
$$

This value is not exhibited by adverbs like intelligemment (cleverly) : (30) does not require a personalisation of the computer to be acceptable.

$$
\begin{aligned}
& \text { L'ordinateur a traité le problème intelligemment. } \\
& \text { The computer processed the problem cleverly. }
\end{aligned}
$$

As the latter adverbs do not contradict the epistemic value of durative achievements, we understand why they can modify them without problem, as suggested by (28) above ${ }^{7}$.

To be comprehensive, one should still explain why a sentence like (27) cannot be saved by applying the adverb to the event this sentence

latter one, because achievements are always compatible with agent-oriented adverbs under the agentive reading. The problematic one is the manner reading.

7 It goes without saying that a lot more remains to be said about the difference between adverbs like cleverly and carefully. My only goal is to show that their distribution differs with achievement predicates (contrary to what is often assumed), and to suggest that it is the conflict between the respective epistemic value of achievement verbs and attentional predicates which explains their incompatibility. 


\section{Fabienne Martin}

presupposes, namely, something like a playing of the game. Indeed, this event is a standard action in the usual sense of the term, and one can certainly play a game carefully. In Martin $(2006,2007)$ I propose to exclude this possibility of saving sentences like (27) by the following principle (see also Piñón 2007 for a similar proposal) :

(31) An adverb can modify an event whose occurrence is presupposed by a verb if and only if it modifies in the same way the event(s) whose occurrence is asserted by the same verb.

According to this principle, attentivement could modify the playing presupposed by (27) if and only if it modifies the winning, which is excluded for other reasons just mentioned.

\section{No partial completion}

If we suppose that achievements can in principle be coerced into durative predicates when needed, we should explain why they are always unacceptable with certain « durative-only » items like adverbs of completion or the aspectual verb arrêter (stop) :

\footnotetext{
* Pierre a partiellement trouvé la clé.

* Pierre partly/partially found the key.

* Pierre a arrêté de trouver la clé.

* Pierre stopped finding the key.
}

Caudal (1999) proposes to account for this in stating that these (durative) predicates are, in his terms, atomic. He defines atomic predicates as predicates denoting events which do not have proper parts. As such, durative achievements are incompatible with items like adverbs of completion or the aspectual verb stop, entailing the existence of such proper parts. On this view, the agrammaticality of (32)-(33) reflects an ontological problem.

However, as long as we stick to a non-conceptualist realist framework, where events denoted by sentences are supposed to be real mundane events, it is very hard to admit the existence of durative events without proper parts. In fact, this amounts to a contradiction in terms. It is a valid option only if we suppose, like Caudal, that events denoted by sentences are non-real conceptual entities. Then it becomes possible to associate two properties with a sub-class of conceptual events - durativity and atomicity - which cannot be simultaneously verified by real events.

Another solution, which does not force giving up realism is to analyse the unacceptability of (32)-(33) as a semantic problem. Before going further, it is worthwhile to note that a first subclass of achievements is compatible with complètement (completely) but not with partiellement, $c f .(34)$, while a 
Revisiting the distinction between accomplishments and achievements

second class is compatible neither with partiellement, nor with complètement, $c f$. (35)). Let us call the first class persuader-verbs, and the second class atteindre-verbs ${ }^{8}$.

Pierre a OK complètement $/ *$ partiellement persuadé tout l'auditoire.

Pierre completely/partially/partly persuaded the whole audience. ${ }^{9}$

* Pierre a complètement/partiellement atteint le sommet.

* Pierre completely/partially/partly reached the summit.

Now, let us suppose, as suggested by Piñón (2005a), that the semantics of adverbs of completion makes reference to the degree $d$ to which an event is realised, $d$ taking its value between 0 and 1 . In the case of complètement, the degree of realisation of the event is maximal $(d=1)$ and in the case of partiellement, it is partial $(0<d<1)$. Let us assume, besides, that the semantics of arrêter also makes reference to a degree $d$ to which the event is realised, with $0<d<1$ when the event is telic. We can then reformulate the facts illustrated in (32)-(35) in the following way. Items making reference to a degree $d$ are compatible only with telic verbs providing a degree argument ${ }^{10}$. A first class of durative achievement verbs, including atteindre-verbs, do not come with such an argument. For this reason, these predicates are incompatible with complètement, partiellement, and arrêter. A second class of durative achievement verbs, including persuader-verbs, have a degree

8 In fact, atteindre-verbs are also incompatible with achever (finish), cf. * Il a achevé d'atteindre le sommet (He finished reaching the summit), while persuader-ones tend to accept it more easily, cf. (?) Il a achevé de me persuader (He finished to persuade me). I come back to this correlation between the (un)acceptability of complètement and achever below.

9 The English verb persuade is less of a prototypical achievement than its French counterpart persuader, since it seems to be acceptable with partly and partially. Partiellement persuader sounds completely agrammatical in French, at least when the adverb must apply to the event as in (36), where it cannot scope over the object, given the presence of the adjective tout. I found no occurrence of it in corpora, except one on Internet, but with a plural object. As we will see below, convaincre (convince) is different, since it is perfectly normal with partiellement.

10 The idea that verbs have a degree argument has been proposed and motivated by several authors. Hay et al. (1999) and Kennedy \& Levin (2002) have developed a degree-based analysis for degree achievement verbs, and claim that it can be extended to all verbs with an incremental theme (though without filling out the details). Piñón (2007b) offers a concrete alternative theory to theirs and provides several empirical facts in favour of a degree-based analysis of predicates in general. 


\section{Fabienne Martin}

argument, but lexically fix it to $1^{11}$. In other words, predicates of this kind cannot be used to denote an incomplete event. (Note that this is very different from saying that the events denoted by these predicates do not have proper parts.) This is why verbs of this second kind are not compatible with partiellement or arrêter, which require $d$ to be less than $1^{12}$. However, as they still provide a degree argument, they can be modified by complètement or achever (cf. (15)-(18)), which are happy with their constraint of maximality. A third class of telic verbs, which, by definition, excludes achievement verbs, introduce a degree argument which can take its value between 0 and 1 . This class corresponds to accomplishments (or, as we will see later, to prototypical accomplishments).

Of course, until now, I have only proposed to classify verbs according to the degree argument. Further research is needed to explain this classification through independent properties of the verbs at hand.

\section{No for-phrases}

An obvious common point between accomplishments and durative right achievements is that, as telic predicates, they are supposed to be incompatible with pendant-phrases (for-phrases), at least when the durative adverbial has scope over the event, and not over the resultant state of the event. For instance, (36) is acceptable only on the irrelevant reading where the state resulting from the finding lasts ten minutes :

$$
\begin{aligned}
& \text { \# Pierre a trouvé la clé pendant dix minutes. } \\
& \text { \# Pierre found the key for ten minutes. }
\end{aligned}
$$

However, a closer look at the distribution of pendant-phrases shows that accomplishments and durative achievements differ in this respect too.

Smollett (2005) emphasizes that contrary to the theoretical doxa, a lot of speakers do accept an atelic reading of telic predicates if the context helps to trigger it, as in (37). Her claim seems verified in French too :

Kathleen a mangé une pomme pendant quelques minutes au téléphone.

11 This solution was originally suggested to me by C. Piñon for the verb persuader.

12 Note that the compatibility of these predicates with the progressive does not contradict our claim that they can only be used to denote complete events. Indeed, as we saw earlier, progressive achievement sentences are special precisely because they do not entail the existence of a part of an event which can possibly satisfy the predicate (these progressive sentences do not denote incomplete events). 
Kathleen ate an apple for a couple of minutes while talking on the phone. (Smollett 2005)

On the basis of a collection of examples like (37), Smollett proposes to give up the traditional idea that quantized direct object makes the predicate telic. Piñón (2005a) suggests that more caution is in order, since the coercion operation seems to be available only with a subset of quantized objects, namely, objects of the form a/the $N$ used by Smollett. With two $N$, all the Ns or every $N$, the meaning shift is much more difficult to realise, even with additional contextual support :

\# Kathleen a mangé deux pommes/toutes les noix/la plupart des noix pendant quelques minutes au téléphone.

Kathleen ate two apples/every nut/most of the nuts for a couple of minutes while talking at the phone.

However, the observation of Smollett is interesting because it allows another difference to be made between (prototypical) accomplishments and durative achievements : contrary to the former, the latter never allow the coercion even in the easy case of NPs a/the $N, c f$. (36) and (39)-(40). The reading where the adverbial scopes over the resultant state is ignored for the judgments :

* Pierre a atteint le sommet pendant dix minutes.

* Pierre reached the summit for ten minutes.

* Pierre a trouvé la solution pendant dix minutes.

* Pierre found the solution for ten minutes.

Smollett notes that the atelic reading seems also more difficult to obtain with some accomplishments even with the help of an adequate context, but she does not try to define the class of predicates which easily accept the meaning shift.

What is the property of achievements responsible for the problem? At first sight, one could think that the unavailability of the atelic reading has the same source as the incompatibility with adverbs of completion like partiellement. Indeed, atelic sentences built with a telic verb strongly suggest that the telic point is not reached; for instance, Peter ate an apple for some minutes suggests that Peter didn't finish the apple he was eating. One could then think that verbs unable to describe incomplete events, like the ones which cannot be modified by partiellement, could not be modified by forphrases for the same reason.

Even if there might be something true in this, there are at least two reasons to think that the two facts should not be explained in the same way. Firstly, while sentences with a telic predicate modified by partiellement 


\section{Fabienne Martin}

entail that the event is incompletely realised, sentences with the same predicate modified by a for-phrase seems to only conversationally implicate it. For instance, while (41B') is contradictory, (41B) is not :

(41) [Context : a policeman is interviewing a suspect about his schedule]

A. Qu'avez-vous fait exactement de 17.00 à 17.15 ?

B. Eh bien, j'ai mangé un hamburger pendant cinq minutes (en fait, je l'ai mangé complètement), puis je suis sorti pendant dix minutes au jardin, et enfin j'ai entamé ma sieste.

B'. \# Eh bien, j'ai partiellement mangé un hamburger (en fait, je l'ai mangé complètement), puis je suis sorti pendant dix minutes au jardin, et enfin j'ai entamé ma sieste.

A. What did you do exactly from 17.00 to 17.15 ?

B. Well, I ate an hamburger for five minutes (in fact, I ate it completely), then I went out for ten minutes in the garden, and finally I started my nap.

B'. \# Well, I partially ate an hamburger (in fact, I ate it completely), then I went out for ten minutes in the garden, and finally I started my nap.

From the acceptability of (41B), we can conclude that a telic predicate modified by a for-phrase can be used to describe a complete event only at the cost of cancelling the conversational implicature triggered by for-phrases. I propose to call it the implicature of incompletion.

More decisively, there are some predicates acceptable with partiellement but not with pendant-phrases (in (43), the irrelevant reading where the adverb scopes over the resultant state - I kept the door opened for one minute - is ignored for the judgement) :

J'ai partiellement ouvert la porte.

I partly opened the door.

?? J'ai ouvert la porte pendant une minute.

?? I opened the door for one minute.

I propose to explain the distribution of for-phrase with telic predicates in the following way:

Condition of Iterativity. Call $e$ the event introduced by the predicate and $y$ the entity denoted by its object. A telic predicate $P$ can form an acceptable atelic VP with a pendant-phrase iff for every (relevant) part $e^{\prime}$ of $e$, there is a (proper or improper) part $y^{\prime}$ of $y$ such that $e^{\prime}$ satisfies $P$ and $y^{\prime}$ is the Theme of $e^{\prime}$.

Roughly, the idea is that eat an apple accepts the meaning shift because the eating of an apple is made of an iteration of eatings of parts of the apple, while open the window is not because the opening of a window is not made 
Revisiting the distinction between accomplishments and achievements

of an iteration of openings of (parts of) the window ${ }^{13}$. Let us call iterative accomplishments predicates like eat an apple and non-iterative accomplishments predicates like open the window.

In favour of Condition (44), note that the acceptability of a for-phrase can vary with the same verb if (44) is met or not ${ }^{14}$.

(45) ?? La coiffeuse l'a embellie pendant trente minutes (en lui coupant les cheveux)

?? The hairdresser beautified her for thirty minutes (in cutting her hair)

(46) On a embelli l'appartement pendant deux heures (en faisant des aménagements à gauche et à droite)

We beautified the apartment for two hours (in making some improvements here and there)

?? J'ai réparé l'ordinateur pendant trente minutes.

?? I repaired the computer for thirty minutes.

(48) Maman a réparé ton sac pendant deux heures. Il y avait une dizaine de déchirures.

Mom repaired your bag for two hours. There was a dozen of tears in it.

For instance, in (46), the context makes clear that the whole beautifying is made of several smaller ones, a reading harder to obtain in (45). The same applies to (47)-(48) ${ }^{15}$.

It is interesting to note that even if some accomplishments resemble durative achievements in their difficulty with getting the atelic reading, the problem seems to be less dramatic in their case. For instance, (45) and (47) seem less problematic than (39)-(40). Arguably, the difference comes from the fact that while (45) and (47) only violate Condition (40), (39) and (40) also cancel the implicature of incompletion described above.

13 Note that (44) does not amount to saying that the verb should have an incremental Theme as defined by Krifka (1992). Indeed, mapping to objects (a central property of incremental theme) does not require parts $e$ ' of $e$ to satisfy the predicate $P$.

14 According to one of the reviewers, the examples in (45)-(48) are all equally odd. Note that the difference between iterative and non iterative accomplishments may also be useful to explain when an accomplishment allows the "failed attempt interpretation » in languages like Turkic, Uralic and Noth-Caucasian (Ivanov \& Tatevosov (2006)). Under this interpretation, the Agent performs an activity in order to trigger a change of state of the Patient, but the activity terminates before the change of state is attained, and the Patient remains in its initial state (id.). Some accomplishments only allow this interpretation (the equivalents of sew, write, plow and fill in do, but not the correspondents of open the door, wake up or tear a thread). Interestingly, they are all iterative accomplishments in our classification. 


\section{Fabienne Martin}

\section{3. « Achievement-like » accomplishments}

In the previous section, I showed that the distinction between achievements and accomplishments is still motivated even if we admit that achievements can be coerced into durative predicates, and I explained how the distribution of achievements can still be accounted for without assuming that they are always punctual. Now, I would like to show that two subclasses of nonprototypical accomplishments share some of the features of durative achievements just identified, whilst keeping certain central properties of accomplishments.

\subsection{Resultative accomplishments}

Tuer Pierre (kill Pierre) is paradigmatical of the first kind of accomplishments, which differ dramatically from the canonical manger un sandwich (eat a sandwich). Firstly, this predicate is not an "iterative accomplishment $»$ in the sense defined above, since a killing of Peter is not made of several killings of (parts of) Peter. As predicted by (44), kill Peter is not acceptable with durative adverbials :

* J'ai tué Pierre pendant dix minutes.

* I killed Pierre for ten minutes.

Secondly, tuer Pierre cannot be modified by partiellement or embedded under arreter. According to what is proposed above, this is the symptom of the fact that kill fixes the degree $d$ to which the event is realised to 1 :

* Il a partiellement tué le poulet.

* He partly/partially killed the chicken.

?* J'ai arrêté de tuer le poulet ${ }^{16}$.

?* I stopped killing the chicken.

Thirdly, its progressive does not seem to be implicative. For instance, it is not clear that (52) entails (53) :

Pierre est en train de tuer le chat [in $t]$.

Pierre is killing the cat.

The killing of the cat by Peter is partially completed [in $t]$.

The entailment seems to be blocked for the same reason as with a durative achievement: we are not in a position to know that what is performed by

16 The problem of (51) seems less dramatic than the one raised by (50). I do not try to account for this difference here. 
Pierre is a part of a killing of the cat before its death. In the terms proposed above, tuer Pierre seems to denote " epistemically uncontrollable actions » like durative achievements. Interestingly, several speakers who I asked whether there was an entailment from (53) to (54) answered that they would admit it on the condition that we know that the cat is dead at the end (for instance, in a film which establishes the death of the cat as a fact before showing its killing by Peter). This intuition confirms again that the 'lack of epistemic control to the left' is again responsible for the absence of clear entailment from (52) to (53) ${ }^{17}$.

Fourthly, like durative achievements, tuer Pierre is somewhat strange with adverbs of attention like carefully, which is predicted by our analysis if this predicate denotes actions which are not epistemically controllable ${ }^{18}$.

?? Pierre a (attentivement) tué le chat (attentivement).

Pierre (carefully) killed the cat (carefully).

However, despite these four similarities with durative right achievements, tuer Pierre does not exhibit the specific informational structure of this latter class of predicates. Indeed, contrary to gagner la partie or persuader Pierre, it doesn't presuppose $\left(\rightarrow_{P}\right)$ the occurrence of an event :

Il est possible que le chat ait tué la souris ${ }^{19}$.

17 I am not the only one to have noticed that the progressive of kill is not standard. For instance, Engelberg (2002) assumes that with this verb, the expected imperfective paradox doesn't show up. According to him, a sentence like Peter is killing Mary entails that Peter killed Mary, which is suggested, according to him, by the oddness of a sentence like At five, Rebecca was killing Jamaal but in the end, he wasn't dead. To be sure, this sentence is a bit strange, but I don't agree with Engelberg that the imperfective paradox is suspended with kill. However, his claim that the whole killing is entailed may be seen as an expression of the difficulty of admitting that only part of it is.

18 According to T. Solstad (p.c.), this sentence may be acceptable in a context where, for instance, Pierre wants to sell its fur, or wants to avoid being poisoned by its spine. The analysis above does not account for this variation, nor for his other interesting contrast (which is even more intriguing since disassembling the computer may amount to destroying, because it cannot be assembled anymore, for instance) :

(i) ?? Peter destroyed the computer carefully.

(ii) Peter disassembled the computer carefully.

According to one of the reviewers, the sentence (54) is better when the adverb is postponed to the verb. I personally do not see a difference between the two variants.

19 Note, however, that the presupposition tends to arise in a context where the entity denoted by the subject does not intend to kill the entity denoted by the 


\section{Fabienne Martin}

It is possible that the cat killed the mouse.

$l \rightarrow_{P}$ The cat did something that could have killed the mouse.

I propose to call resultative accomplishments this kind of predicates which do not presuppose an event but still resemble right achievements by their incapacity to denote an incomplete event and their incompatibility with the standard progressive.

\section{2. (Strictly) Strong Accomplishments}

Guérir/convaincre Marc (cure/convince Marc) are examples of another class of verbs which seem to straddle the two aspectual classes. Like achievements, they tend to presuppose the occurrence of an event ; cf. (12) above. For instance, (57b) is strange because it cancels the presupposition triggered in (57a) that the doctor did something which could have cured her (e.g., he treated her). Note that soigner (treat) is very different from guérir (cure) on this respect :

(56) a. Le médecin ne l'a pas soignée. b. Elle n'a pas pu aller à l'hôpital. The doctor didn't treat her. She couldn't go to the hospital.

(57) a. Le médecin ne l'a pas guérie. b. \#Elle n'a pas pu aller à l'hôpital. The doctor didn't cure her. \#She couldn't go to the hospital.

Like achievements, they are not straightforwardly compatible with adverbs of attention, as already observed in (11) above.

However, unlike achievements, they are compatible with partiellement and with some aspectual verbs like commencer or cesser (to cease) :

Nous étions tous du même avis: il nous a seulement partiellement convaincus.

We all had the same opinion : he only partly convinced us.

(59) Au début, je trouvais son discours vraiment séduisant. Et puis tout à coup, quand il a évoqué l'hérédité, il a cessé de me convaincre.

At the beginning, I found his discourse really seducing. And then suddenly, when he evoked heredity, he ceased to convince me.

(60) Le médecin a partiellement guéri mon œil droit.

The doctor partly cured my right eye.

object. This has been observed independently by Vecchiato (2004) and Martin (2005). Vecchiato offers a semantic explanation (basically, according to her, kill combined with intentionally and kill combined with unintentionally are two different predicates), while I preferred a pragmatic one based on the Maxim of Quantity in Martin (2006). 

mieux. Et puis tout à coup, le traitement a cessé de le guérir.

At the beginning, the medicines were very efficient and he was getting better and better. And then suddenly, the treatment ceased to cure him.

Note, however, that for the examples (59) and (61) to be acceptable, the aspectual verb must only have the change of state in its scope. For instance, (59) is not natural if it is intended to mean that the subject stopped trying to convince me ${ }^{20}$.

The distribution of verbs like guérir and convaincre can be accounted for in the following way. These predicates presuppose the action of the entity $x$ denoted by the subject, and assert the change of state of the entity $y$ denoted by the object. As an adverb cannot modify an event presupposed by a verb without modifying the event asserted by this verb in the same way ( $c f$. the principle (31)), adverbs of attention are rejected (cf. (11)), since they cannot qualify the change of state of $y$. If we additionally assume that aspectual adverbs cannot take a presupposed event in their scope, we explain the interpretation needed to make (59) and (61) acceptable (what ceases is the asserted change of state, not the presupposed action of the subject). So far, guérir and convaincre resemble durative achievements. The difference is that these predicates can be used to assert the occurrence of an incomplete change of state, which explains their compatibility with partiellement and arrêter (cf. (59)-(62)). On this point, they resemble canonical accomplishments.

Piñón (2006) calls strong accomplishments the predicates which can presuppose the initial part of the event described, and weak accomplishments the predicates which are not able to do so. In English (and French), accomplishments are all strong by default. For instance, I almost ate my sandwich can mean that I didn't finish eating the sandwich (the initial part is presupposed, the scalar reading is obtained) or that I didn't even begin to eat it (no eating is presupposed, the counterfactual reading is obtained). This ambiguity of accomplishments explains why they have two readings when modified by almost. Piñón observes that some languages like Hungarian have weak accomplishments, that is, predicates which can only trigger the counterfactual reading combined with negation or adverbs like almost. I propose to call strictly strong accomplishments the complementary class of accomplishments including convaincre and guérir, which can only have the scalar reading in these contexts.

20 Interestingly too, the aspectual verb arrêter seems less acceptable in these sentences than its near synonymous cesser. I personally accept (59) and (61) on their arrêter variants, but quite a few subjects accept them only with cesser. I do not have an explanation for these contrasts. 


\section{Conclusions}

In this paper, I showed that right achievements coerced into durative predicates still differ from accomplishments in several respects: (i) presupposition of an event, incompatibility with (ii) the standard progressive, (iii) adverbs of attention, (iv) adverbs of completion, (v) durative adverbs, (vi) aspectual verbs like arrêter. I also explained their distribution. Furthermore, I identified two classes of non-prototypical accomplishments resembling durative right achievements (resultative accomplishments like kill share their properties (ii) to (vi), while strictly strong accomplishments like cure exhibit the properties (i) and (iii)), and explained the distribution of forphrases with telic predicates through the distinction between iterative and non-iterative accomplishments. The typology of telic predicates emerging from this new classification is more fine-grained than the traditional one, but it seems to be justified at least by French and English data, and hopefully for other languages as well.

\section{References}

Caudal, P. (1999). Achievements vs. Accomplishments: A Computational Treatment of Atomicity, Incrementality, and Perhaps of Event structure, in: Proceedings of Taln99, Cargèse. Available at $<$ http ://www.llf.cnrs.fr/fr/Caudal $>$

(2002). Stage Structure and Stage Salience for Event Semantics, paper presented to the Workshop on the Syntax and Acquisition of Aspect, University of Iowa, Iowa City (IA), U.S.A., May 2002. Available at $<$ www.uiowa.edu/ linguist/workshop/pdf/Caudal.pdf $>$

Engelberg, S. (1999). The Magic of the Moment - What it Means to be a Punctual Verb, in: S. Chang; L. Liaw; J. Ruppenhofer (eds), Proceedings of the Twenty-Fifth Annual Meeting of the Berkeley Linguistics Society, Berkeley : Berkeley Linguistic Society, 109-121.

-- (2000). Verb Meaning as Event Structure, in : A. Lommel.; A. Melby. (eds), Proceedings of the 26th LACUS Forum, Edmonton, August 1999, Edmonton, 257-268.

------- (2002). The Semantics of the Progressive, in: A. Cynthia (ed.), Proceedings of the 2001 Conference of the Australian Linguistic Society.

Freed, A. (1979). The Semantics of English Aspectual Complementation, Dordrecht/ Boston/ London : D. Reidel Publishing Company.

Geuder, W. (2000). Oriented adverbs, doctoral dissertation, Universität Tübigen.

Hay, J. ; Kennedy, C. ; Levin, B. (1999). Scalar structure underlies telicity in « degree achievesecrements », in: T. Matthew; D. Strolovitch (eds), 
Proceedings of Semantic and Linguistic Theory 9, Ithaca: CLC Publications, 127-144.

Ivanov, M.; Tatevosov, S. (2006). Event structure of non-culminating accomplishments, hand-out of a talk delivered at the Tam-Tam Workshop, Radboud University, Nijmegen, 15 November 2006.

Jayez, Jacques (1996). Référence et aspectualité. Le problème des verbes dits " aspectuels », Cahiers de Linguistique Française, 18 : 275-298.

Kearns, K. (2003). Durative Achievements and Individual-Level Predicates on Events, Linguistics and Philosophy, 26/5 : 595-636.

Kennedy, C. ; Levin, B. (2002). Telicity corresponds to degree of change, hand-out of a talk to Topics in the Grammar of Scalar Expressions, UCLA, January 2002. Available at $<$ http ://semantics.uchicago.edu/kennedy/docs/telicity.pdf $>$

Malink, M. (2007). Right Boundary Achievements under Conative Negation, in : A. Steube (ed.), Sentence and context [working title], Berlin/NewYork: Mouton de Gruyter. Available at <http ://pinon.sdfeu.org/covers/nrbacm.html>

Martin, F. (2005). Les deux lectures de faillir+inf. et les verbes présupposant l'existence d'un événement, in : B.-Z. Shyldkrot; N. Le Querler (eds.), Les Périphrases verbales, Amsterdam : Benjamins, 455-473.

-------- (2006). Prédicats statifs, causatifs et résultatifs en discours. Sémantique des adjectifs évaluatifs et des verbes psychologiques, doctoral dissertation, Université libre de Bruxelles.

(2007). 'Non-Agentive Verbs' Presupposing an Event. Psych-verbs and Agent-Oriented Adverbs; hand-out for a paper delivered at the conference Forces in Grammatical Structures, January 2007. Available at $<$ http ://www.uni-stuttgart.de/lingrom/martin/pdf/2lf_martin.pdf $>$

Mittwoch, A. (1991). In Defence of Vendler's Achievements, Belgian Journal of Linguistics, $6: 71-85$.

Parsons, T. (1985). Underlying events in the logical analysis of English, in : E. Lepore; and B. McLauchlin (eds), Actions and events : perspectives on the philosophy of Donald Davidson, Oxford : Blackwell, 235-267.

Piñón, C. (1997). Achievements in an Event Semantics, in: A. Lawson, Aaron; E. Cho (eds), Proceedings of Semantics and Linguistic Theory 7, Ithaca, New-York, CLC Publications : Cornell University, 273-296. (2005a). Adverbs of Completion in an Event Semantics, in : A. van Hout ; H. de Swart, H. Verkuyl (eds), Proceedings of Perspectives on Aspect, Dordrecht : Kluwer Academic Press, 149-166.

- (2005b). A problem of Aspectual Composition, manuscript.

(2007a). Negating Right Boundary Achievements (Comments on Malink), in A. Steube, (ed.), Sentence and context [working title], Berlin/New-York : Mouton de Gruyter. Available at $<$ http ://pinon.sdfeu.org/covers/nrbacm.html> 


\section{Fabienne Martin}

(2007b). Aspectual composition with degrees, in : L. McNally ; C. Kennedy (eds), Adjectives and adverbs in semantics and discourse, Oxford : Oxford University Press.

Ryle, G. (1949). The Concept of Mind, Harmondsworth : Penguin/Peregrine Book.

Smollett, R. (2005). Quantized Direct Object Don't Delimit after all, in : A. van Hout ; H. de Swart ; H. Verkuyl (eds), Proceedings of Perspectives on Aspect, Dordrecht : Kluwer Academic Press, 41-59.

Tenny, C. (1987). Grammaticalizing Aspect and Affectedness, Doctoral Dissertation, Massachusetts Institute of Technology.

Vecchiato, A. (2004). On Intentional Causation in Italian, in : J. Auger; J. Clements; B. Vance (eds), Contemporary Approaches to Romance Linguistics. Selected Papers from the $33^{\text {rd }}$ Linguistic Symposium on Romance Languages, Current Issues in Linguistic Theory 258, Amsterdam : John Benjamins, 343-360.

Vendler, Z. (1957). Verbs and Times, Philosophical Review, 66 : 143-160.

Verkuyl, H. (1972). On the compositional nature of the aspects, Dordrecht : D. Reidel Publishing Company.

Zybatow, T. (2004). Achievements: Two Experimental Studies and One Semantic Analysis, Talk delivered at Sinn und Bedeutung 9, Nijmegen, 1-3 November 2004. 